\title{
CUANDO LA CULTURA SE CONVIERTE EN POLÍTICA
}

\section{RODRIGO MONTOYA ROJAS}

Profesor Emérito de la Universidad Nacional Mayor de San Marcos

\section{Resumen.}

La reflexión que he escrito para esta ocasión trata de la relación entre la antropología y la realidad, entre la cultura y la política, entre los pueblos indígenas y el poder. En la primera parte, centro mi atención en los conceptos y en la conversión del objeto de estudio de nuestra disciplina en sujeto, en la extraordinaria transformación del concepto de cultura en política, en la victoria de la diversidad cultural sobre la uniculturalidad del Estado nación, y en la réplica frente a esa victoria desde el poder. En la segunda parte trato de mostrar el proceso de aparición y cambio de las categorías que usamos en Perú para nombrarnos e insultarnos; es decir, de habitantes de América a indios, de indios a campesinos, de campesinos a indígenas. Cierro esta reflexión con una mirada histórica sobre lo que la palabra Perú quiso y quiere decir y sobre el porvenir de la cultura quechua. Mi texto "Con los rostros pintados: tercera rebelión amazónica en Perú (agosto 2008-junio2009)", (Montoya, 2009) presenta el momento cumbre en el que la cultura se convierte en política. Me parece que este acontecimiento es trascendental en la historia del país y en el desarrollo de nuestra disciplina.

Palabras clave: Perú, pueblos indígenas, política, cultura, antropología, diversidad cultural. 


\begin{abstract}
.
The reflection I have written for this journal is about the relationship between anthropology and reality, between culture and politics, between indigenous peoples and power. In the first part, I focus on the concepts and the conversion of the reaearch objects of our discipline into subjects, in the extraordinary transformation of the concept of culture into politics, in the victory of cultural diversity over the uniculturality of the Nationstate, and in the reply of power to that victory. In the second part, I attempt to show the proccess of emergence and change of the categories we use in Perú to name and insult among us; that is, from American inhabitants to indians, from indians to peasants, from indians to natives. I finish this reflection with an historical view on what the word Perú attempted to mean and currently means, and on the future of quechua culture. Mi text "Con los rostros pintados: tercera rebelión amazónica en Perú (agosto 2008-junio2009)", (Montoya, 2009) llustrates the peak of the process of convertion of culture into politics. It seems to me that this event has far-reaching implications for both the history of the country and the development of our discipline.
\end{abstract}

Key words: Peru, indigenous peoples, culture, policy, anthropology, cultural diversity.

\title{
1. TEORÍA Y REALIDAD POLÍTICA
}

\subsection{Antropología y pueblos indígenas: de simple objeto a objeto-sujeto}

Si hoy, una antropóloga o un antropólogo llega a un pueblo indígena en alguno de los países de América Latina y, tal vez, del mundo, debe explicar qué busca, pedir permiso, comprometerse a devolver los saberes que obtenga y a acompañar a ese pueblo en sus gestiones y movilizaciones para conseguir que por lo menos parte de sus problemas se resuelva. En tiempos de Malinowsky y su clásico viaje a las islas Trobriand no ocurría eso; tampoco cuando entre 1960 y 1970 los antropólogos de mi generación iniciamos nuestros primeros pasos en eso que llamábamos trabajo de campo en serio. En los últimos 40 años se han producido dos grandes cambios: de un lado, nuestro objeto de estudio se ha convertido en sujeto; $y$, de otro, el concepto de cultura se ha vuelto política. En otras palabras, sin abandonar la academia uno de nuestros conceptos claves vuelve sobre la realidad y es parte de la política, más allá de lo que los antropólogos quieran o no. José Carlos Mariátegui, en 1927, anunció que las reivindicaciones culturales se convertirían en políticas y que cuando ese cambio se produzca los llamados indios serían actores de su propia liberación (Montoya, 1990). Nuestra diversidad cultural en cada uno de los países de América -que existe desde hace miles de años, y fue invisible para los Estados Naciones uniculturales, desde 1800 hasta aproximadamente, 1980- es tomada en cuenta ahora como un elemento clave en la política de los Estados naciones. No por gusto la interculturalidad, que deriva directamente de la pluri o multiculturalidad, es 
recomendada por el Banco Mundial como propuesta "transversal" para sus proyectos, propuesta que es repetida al pie de la letra por los gobiernos llamados nacionales, y asumida como una moda más por la cooperación internacional, las financieras de proyectos y las ONGs. El "eje transversal de la interculturalidad” aparece también en la investigación de las disciplinas sociales como algo natural, sin la crítica debida.

Entre el objeto de estudio dela Antropología y los antropólogos no existe la misma relación que entre biólogos y hormigas. Somos seres humanos quienes constituimos el objeto y sujeto de estudio. Este hecho era el mismo en tiempos de Taylor (1871) y el comienzo de la Antropología; lo que cambió fue la percepción de esa realidad. Por decisión propia, los indígenas no aceptan más ser considerados como "salvajes", "bárbaros", "inferiores" o "menores de edad". Lejos, muy lejos de donde se toman las decisiones políticas, en el mundo académico, muchas voces de la antropología en América Latina dijimos también lo mismo, de diversos modos. Todo comenzó a cambiar decisivamente cuando los niños y jóvenes indígenas fueron a las escuelas, colegios y universidades y se dieron cuenta de que sus culturas no eran tomadas en cuenta, que sus lenguas eran utilizadas sólo para traducir "la palabra de Dios", esa del Nuevo testamento, que desde 1940, llevan los misioneros del Instituto Lingüístico de Verano (ILV) a los pueblos indígenas en más de cien países del mundo. El paso siguiente, fue organizarse étnicamente para defender sus culturas, lenguas e identidades. Después, quedaba el desafío de organizarse políticamente para estar en mejores condiciones de defender sus derechos étnicos y pensar sus problemas como parte de realidades nacionales y globales. Desde los inui en Canadá, hasta los mapuches en Chile, ese ha sido, en muy gruesas líneas, el gran proceso de cambio. En Perú, la rebelión amazónica de Bagua de agosto de 2008 y junio de 2009, es el peldaño reciente. Han surgido generaciones de intelectuales indígenas, bi o trilingües, ciudadanos étnicos y nacionales (mexicanos, ecuatorianos, peruanos, bolivianos, etc.) que tienen un juicio crítico de la realidad de sus pueblos, que proponen alternativas de cambio y proyectos políticos no sólo para sus pueblos sino para los países, de los que estos pueblos forman parte. La victoria de Evo Morales y la nueva Constitución del "Estado plurinacional de Bolivia", en reemplazo de la "República de Bolivia" como Estado nación, representa el punto más alto de la emergencia indígena como nuevo actor en el escenario político Latino Americano.

\subsection{Cultura: proceso de conversión desde un concepto teórico a una categoría política.}

Entre los concepto de las disciplinas sociales, el de cultura ha tenido una fortuna muy particular. Deriva del latín culture que quería decir simplemente cultivo. En por lo menos seis siglos, en las llamadas ciencias agronómicas o ciencias de la tierra, se dan hoy cursos de cultura de la vid, el azúcar o el maíz. Por mediación de los que se llamarían antropólogos pasó del mundo de la agricultura y la vida cotidiana a salones académicos 
para representar el modo de vivir, sentir y dar sentido, de cada uno de los pueblos en el mundo. La originaria metáfora del cultivo se reproduce constantemente porque cada cultura tiene su propio modo de cultivar; es decir, educar y formar a sus individuos, desde la leche materna y a lo largo de toda la vida. En los círculos universitarios la nueva categoría fue enriqueciéndose, volviéndose cada vez más compleja. En un recuento de acepciones, orientaciones y segmentos de la realidad conocidos con ese concepto, he identificado treinta y cuatro: 1 , Cultivo agrícola, 2 , modo y estilo de vida, 3 , civilización, civilizar, 4, sociedad primitiva, pueblo indígena, 5, sólo una cultura, no diversidad, pluri o multi, 6, moderna, tradicional y mestiza, 7, una "clase" dentro de la estratificación social, 8 , áreas culturales, 9 , subculturas, 10 , transculturación, aculturación y desculturación, o deculturación, 11, colonialismo interno, dominación cultural e imperialismo cultural, 12 , folklore como cultura urbana popular, 13, cultura popular, 14, cultura pop, 15, arte mestizo, 16, cambio cultural, 17, revolución cultural, 18, cultura de la pobreza, 19, Mal estar en la cultura como original propuesta de Sigmund Freud, 20, culturas híbridas, 21, contracultura, 22, cultura como mentalidad e imaginario, 23, cultura igual bellas artes: página cultural de periódicos y revistas, 24 , conocimiento, saber de, 25, política cultural, 26, patrimonio material e inmaterial, 27, relativismo cultural, 28, crítica literaria postmoderna: cultura como una ficción inventada por antropólogos y como narrativa, 29, diversidad cultural, mundo de lo pluri y multi, 30, interculturalidad, 31, 32, multiculturalismo, 33, cultura igual Pueblo indígenas desde la orilla de los intelectuales indígenas, 34, Culturas a plenitud y a medias.

Lo notable es que en los últimos 40 años, precisamente en el tiempo que tienen los movimientos indígenas -étnicos y políticos- los pueblos indígenas se identifican con el concepto cultura y se produce un feliz encuentro-reencuentro de la teoría con la realidad de la Antropología con los pueblos indígenas u originarios. Hoy, en América Latina la categoría cultura ocupa cuatro espacios claramente identificables. En el primero, se confunde con lo que en los medios de comunicación se llama "página cultural"; es decir, arte, literatura, teatro, cine, pintura, música clásica o "culta", museos, patrimonio, y, últimamente, gastronomía. En el segundo, es entendida como el saber escolarizado, e identifica la lectura y escritura con sabiduría en oposición a la supuesta ignorancia de los analfabetos. El tercero, es el espacio antropológico clásico del modo de vivir, pensar, plantear y resolver problemas, sentir y dar sentido y etc. etc. El cuarto, se encuentra en el lenguaje de las organizaciones indígenas étnicas y políticas en las que cultura quiere decir simplemente pueblo indígena. En los dos primeros espacios el concepto sirve al poder y es parte de la colonialidad, como un recurso aparentemente científico para presentar y justificar su orden de desigualdad. En los dos últimos, puede servir en determinadas condiciones para la emancipación, libertad y descolonialización. 


\subsection{Réplica desde el poder: hay que cambiar en algo las cosas para que todo siga igual}

(Giuseppe Tomassi de Lampedusa, "El gato pardo"). Interculturalidades de hecho y deseada.

A fines de 1970, estaban ya colocados los primeros cimientos de lo que sería la emergencia de organizaciones étnicas y políticas en América Latina. Para las clases políticas y los medios de comunicación, todo parecía igual. El katarismo en Bolivia, como identificación con y reivindicación de Túpac Katari, el dirigente aymara en la rebelión contra el imperio español en 1780, al lado de Túpac Amaru, fue una especie de embrión decisivo de lo que vendrían a ser después la multitud organizada de El Alto y el Movimiento al Socialismo, MAS, de Evo Morales. Los partidos de la clase política profundamente influidos por el poder colonial, no tuvieron interés alguno en lo que hacían los llamados indios, considerados como simples menores de edad objeto de protección y amparo. Lamentablemente, el marxismo ortodoxo y dogmático de gran parte de las organizaciones de izquierda no fue capaz de prestar la atención debida a la relación profunda que existe entre la cultura y la política, y no supo ver a los llamados indios movilizándose y actuando por cuenta propia. Lo que ocurría con los indígenas andinos y amazónicos en Ecuador y con los pueblos indígenas en Chiapas, era simplemente invisible. Para los servicios de inteligencia de los Estados Unidos, se trataba -seguramente- de algo nuevo que debía ser examinado y seguido con particular atención. En el continente, Estados Unidos es el único país que tiene un enorme servicio de inteligencia -policías y académicos, no siempre juntos- que examina los escenarios políticos a corto, mediano y largo plazo. Hace muchísimo años que advirtieron del peligro indígena en el continente.

No se requiere de demasiada osadía para suponer que después del "Levantamiento indígena en Ecuador", la "Marcha por la dignidad y el territorio" en el oriente boliviano - ambas en 1992, sin que existiese comunicación alguna entre ellas- y la aparición del Ejército Zapatista en México, 1994, los ideólogos y consejeros del poder colonial confirmaron sus proyecciones y trabajaron para dar la líneas gruesas de lo que sería y es una política global para bloquear la emergencia indígena, cooptar a sus dirigentes, neutralizar y reorientar las reivindicaciones indígenas. En esa perspectiva, fue indispensable que el Banco Mundial obtuviese la complicidad de los gobiernos nacionales. Con extraordinaria astucia los grandes funcionarios del BM convencieron a los gobiernos para solicitar préstamos al BM y que éste formule y realice proyectos de desarrollo para los pueblos indígenas. $\mathrm{El} \mathrm{BM}$ hace lo que le parece y los gobiernos pagan sus préstamos e intereses correspondientes. El caso ecuatoriano desde 1995 es el más ilustrativo. Con lamentable torpeza, los gobiernos nacionales dejan que el BM haga lo que quiera. Ya tenemos dos décadas de préstamos y proyectos de desarrollo. Si se toma en cuenta los primeros proyectos de 1940, luego de 70 años de proyectos, el llamado desarrollo no tiene por dónde aparecer. Permítaseme contar aquí una historia de lo ocurrido con la Dirección 
de Educación Bilingüe Intercultural, EBI, en el Ministerio de Educación de Perú. En su primer gobierno, Alan García (1985-1990) creó la dirección EBI atendiendo un pedido de las organizaciones indígenas y de los proyectos privados de EBI existentes en el país. Un director, una secretaria y cuatro sillas, fue todo lo que aquel gobierno ofreció. Alberto Fujimori, el ciudadano japonés presidente de Perú, en su primer gobierno, alrededor de 1991, cerró esa dirección de EBI. Unos años después, volvió a crearla porque el BM le dijo que no apoyaría proyectos en educación si su gobierno no asumía la EBI como parte de su propia política. Una de las claves para ese cambio es la categoría de interculturalidad. Hoy, en las políticas nacionales de países con fuerte composición indígena, parece que todo "es" intercultural. Es pertinente detenerse en esta propuesta para examinarla con extremo cuidado. El punto de partida es la diversidad cultural, invisible y negada durante siglos; luego, convertida en recurso, particularmente turístico, de cada país. Al hablar de interculturalidad es indispensable distinguir una interculturalidad de hecho y una interculturalidad deseada. Confundir estos dos espacios conduce a caer en un error teórico de graves consecuencias políticas. Existe una interculturalidad de hecho en zonas de coexistencia de diferentes culturas dentro de los países y en zonas de fronteras de los Estados naciones. Alrededor del lago Titicaca, frontera entre Bolivia y Perú, por ejemplo, hay millares de personas bi y trilingües que hablan quechua, aimara y castellano. Al margen de toda preocupación académica y teórica, estas personas pasan de una cultura a otra como quien cambia el dial de una radio para pasar de un programa a otro. De modo natural se sitúan como nosotros o los otros, de arriba o de abajo y el entendimiento entre ellos y ellas está asegurado, sin que ese entendimiento produzca cambio alguno en las relaciones de desigualdad entre las culturas. La interculturalidad deseada es un ideal, una especie de sueño de las organizaciones indígenas, que supone el respeto, la igualdad y el diálogo entre las culturas o las personas. A los defensores de esta interculturalidad les gustaría que la realidad no sea como es sino como a ellos y ellas les gustaría que fuera. Cuando el Ministerio de Educación peruana dice por encargo del Banco Mundial que la educación peruana es intercultural, impone una lamentable confusión entre la realidad y el ideal de una realidad distinta.

En parte de la historia del concepto, la interculturalidad estuvo directamente ligada a la cuestión lingüística. En un primer y largo período, la educación bilingüe fue propuesta como un instrumento para traducir las llamada "palabra de Dios" del "Nuevo testamento" a las lenguas indígenas, y como un viaje de ida y vuelta entre las lenguas I (indígena) y II (castellano) y la atención particular en el aprendizaje del castellano. En un segundo momento, los dirigentes indígenas reclamaron que la Educación Bilingüe, fuese intercultural, además de bilingüe, en el preciso sentido de tomar en cuenta las creencias, saberes, mitos y espiritualidad propiamente indígenas. En un tercer momento, lo intercultural comienza a desligarse de la cuestión de la lengua, y ahora, en los últimos 
años, la interculturalidad en educación pasa a un segundo plano porque aparece una nueva propuesta del Banco Mundial: la "educación rural". Otra dimensión de la categoría interculturalidad tiene que ver con una aparente igualdad entre las culturas. Lo que ocurre en realidad es que dentro de lo que llamamos diversidad, multi o pluri culturalidad sólo hay una cultura a plenitud y un vasto conjunto de culturas subalternas, minorizadas, o, simplemente, a medias. Con la invasión europeo-española de 1492, concluyen los desarrollos independientes y autónomos de las culturas y pueblos americanos. Plena es la cultura occidental criolla, en la medida en que: 1, ejerce el poder colonial en cada uno de los Estados naciones mientras que todas las culturas existentes están excluidas de participar en la esfera del poder. 2, su lengua es oficial y, 3, su religión y su Dios siguen siendo considerados como únicos y verdaderos. En esas condiciones, la reproducción de los elementos de las culturas indígenas es sólo parcial y éste es un hecho de particular importancia.

Promover y buscar relaciones interculturales en condiciones de igualdad, respeto y diálogo es un loable deseo. Entre el discurso y la realidad se encuentran el poder con toda su fuerza, en sus formas abiertas y encubiertas, y el racismo. En la rebelión amazónica peruana de 2008, por ejemplo, reapareció el viejo racismo colonial, que considera a los pueblos indígenas como salvajes, "chunchos", supuestamente opuestos al desarrollo y a la modernidad. Pedro Pablo Kuczynsky, un ciudadano norteamericano que conserva la nacionalidad peruana, ex primer ministro y que quiere ser presidente de la república, está convencido de que los que en Perú nacimos a más de tres mil metros de altura no pensamos y, por eso, no estaríamos en condiciones de opinar sobre las bondades del Tratado de Libre Comercio con Estados Unidos. Antero Flores Araos, un político social cristiano, catoliquísimo, ex Ministro de defensa del actual gobierno de Alan García, cree también que no tiene sentido consultar sobre el mismo Tratado a los quechuas y aimaras, cusqueños a quienes llama "auquénidos" -es decir, llamas, alpacas, guanacos y vicuñas, variedades de camélidos sudamericanos- y que si defienden el patrimonio cultual de esa ciudad, "se queden con su Machu Pikchu", como si ese gran monumento Inca fuese sólo cusqueño y no peruano. Un periodista de apellido Bedoya en el Diario El Correo recomendó a las fuerzas armadas y policiales usar napalm para resolver el problema de la rebelión amazónica ${ }^{1}$.

1. Un ejemplo del racismo en Bolivia. Con un lenguaje más brutal y directo, el mismo racismo se expresa en Bolivia: "De rodillas indios de mierda, griten viva la capitalidad", "Sucre se respeta carajo", "Llamas, pidan disculpas", fueron las consignas impuestas por un grupo de jóvenes chuquisaqueños que mediante patadas y puñetes obligaron a cerca de 50 campesinos quechuas a quitarse las camisas, ponerse de rodillas y quemar la bandera del MAS y la wiphala (símbolo de las naciones originarias) en pleno frontis de la Casa de la Libertad ubicada en la plaza principal de Sucre (Contreras Baspineiro, 2008). 


\subsection{Victoria de la diversidad cultural sobre la uniculturalidad del Estado nación.}

En 1888, Manuel González Prada (1960), en su discurso leído en el teatro Politeama, afirmó rotundamente que los criollos descendientes de españoles no son verdaderos peruanos, que son los indios los verdaderos peruanos y que el Perú comienza en los contrafuertes andinos. Lima no es el Perú. Cusco es el Perú. Lima es Perú, Cusco no. Así comenzó un debate aún no concluido. En 1889, Clorinda Matto de Turner, una escritora cusqueña profundamente católica, publicó su novela Aves sin nido, considerada como uno de los primeros textos del "indigenismo literario", ese estado de ánimo en favor y defensa de los llamados indios, víctimas de hacendados, gobernadores, jueces y curas. Por criticar a los curas fue excomulgada y murió de exilio en Buenos Aires. Manuel González Prada abrió el debate sobre el Perú contemporáneo; le siguieron principalmente, José Carlos Mariátegui, Luis E. Valcárcel, fundador de la antropología peruana en la universidad de San Marcos, José Sabogal, y José María Arguedas, el antropólogo novelista. Todas las sangres, título de la novela de José María Arguedas (1964) fue la metáfora feliz para expresar la diversidad o el mundo pluri o multi cultural del país.

Ellos, desde la universidad y el mundo artístico y académico, y los migrantes andinos que poblaron Lima y las ciudades costeñas desde 1940, hicieron el largo camino para que los llamados indios sean reconocidos como peruanos, y que las culturas indígenas sean tratadas con consideración y respeto. Por esas mismas huellas anduvimos y nos encontramos aún algunos antropólogos peruanos. Los movimientos étnicos y políticos indígenas dieron el paso decisivo para la victoria de la diversidad cultural del país sobre el Estado nacional unicultural.

De la exclusión y la invisibilidad, los pueblos indígenas han pasado a la foto Benetton, aquella en la que sonrientes y hermosos rostros de rasgos biológicos blancos, negros, amarillos, indios, y muchos matices de mestizaje, son presentados en aparente igualdad de condiciones. Si se observa la foto Benetton con rostros y cuerpos de niñas y niños, nos atrapa la ternura y no podemos dejar de exclamar iqué preciosidad! La consigna "todos somos diferentes" -el elogio a la diferencia- es una astuta estrategia mercantil para que la empresa de modas Benetton ofrezca la diferencia individual y exclusiva a precios razonablemente caros, por eso de que lo diferente-exclusivo-bueno debe tener siempre un precio alto. Si Lázaro Cárdenas, José Vasconcelos y otros indigenistas mexicanos resucitasen -sólo digo, es un decir- verían en esa foto su "raza cósmica" y se alegrarían, seguramente. Como es fácil inferir, el primer gran reconocimiento de la diferencia y del derecho a la diferencia, proviene de las canteras capitalistas del saber vender. En la célebre exposición parisina Todos iguales, todos diferentes -en el Museo de Historia Natural, de la calle Jussieu, en 1992 -la especie humana fue presentada en dos grandes fotos: una, por fuera, con todos los rostros posibles para mostrar la diferencia, como la foto Benetton; $y$, otra, como una radiografía en la que los "negros", "indios", "amarrillos", "blancos" y todos 
los mestizos posibles- tenemos los mismos órganos y somos, en esencia, iguales. Esta es la victoria de la diferencia y la igualdad que proviene de las canteras antropológicas, paleontológicas, y biológicas. Por ese camino, el cuento de las "razas", -supuestamente "superiores" e "inferiores" y la llamada "sangre azul" de los aristócratas y burgueses, concluyó como una simple ficción pensada para justificar las diferencias entre los seres humanos con y sin riqueza y poder. Queda pendiente el tema de la igualdad como ideal de la modernidad, y la desigualdad real en la distribución de los recursos existentes en las sociedades humanas. Los intelectuales indígenas y algunos antropólogos preguntamos desde hace muchos años, de qué igualdad estamos hablando, quiénes tienen que ser iguales a quiénes y por qué. Seguir el modelo europeo-norteamericano como supuesto polo mayor de desarrollo logrado hasta ahora, tiene poco o nulo sentido. Desde hace muchísimo tiempo sabemos ya que debajo del paraguas de la igualdad como discurso, en la realidad unos somos más iguales que otros.

\subsection{Diversidad cultural sí, pero Poder no. Folklore, foto Benetton, sí, pero como antes, al margen del poder.}

El triunfo de la diversidad cultural abre pistas contradictorias. De un lado, entusiasma a los pueblos indígenas; de otro, en la orilla del poder global, preocupa y provoca reacciones inmediatas para que los pueblos indígenas no sigan ganando batallas y se queden donde están. Cuando las danzas se lucen como expresiones del arte "nacional" en homenaje a presidentes norteamericanos o europeos en visitas de unas cuantas horas, se produce un doble fenómeno. Es un reconocimiento de hecho del arte indígena, local y universal. Al mismo tiempo, es también una apropiación. En materia artística, las clases dominantes tienen poco que lucir; en contraste, los pueblos indígenas y las clases populares tienen mucho que ofrecer. La "Danza de tijeras", mostrada al presidente Bush hace unos años, fue en otro tiempo objeto de una gran persecución. Por su supuesto "pacto con el diablo", los danzantes fueron perseguidos, encarcelados y torturados. Ahora gozan de buena salud.

Estamos ya habituados a oír frases como las siguientes: “Qué precioso es el folklore!”, " $i$ Qué lindo es el arte indígena!" Sí, pero por favor "que los llamados indios se queden donde están", "no pretendan cuestionar y menos tomar el poder". "No están preparados para la democracia", "no pueden gobernar", "habría que educarlos primero". Este último argumento se mantiene, ininterrumpidamente, desde el comienzo de las repúblicas en el siglo XIX.

Como las clases políticas no pudieron impedir la victoria de los pueblos indígenas y su diversidad sobre la uniculturalidad del Estado nación, se consuelan con seguir el ejemplo de las empresas capitalistas como Benetton para servirse de esa diversidad y hacer buenos negocios. La riqueza de la diversidad cultural inspira a empresarios, artistas, escritores, pintores, cocineros, cineastas, videastas y políticos en campaña, con una propuesta 
muy precisa: que lo nuevo tenga algo de "ethnic fashion", pero no se confunda con lo propiamente étnico. En el mundo de la moda, no se adopta el vestido indígena como tal, sino se toma y cambia de formas uno o dos fragmentos para incluirlos, dentro del paquete propiamente europeo o norteamericano que define las modas en cada uno de nuestros países. En otras palabras, un "chullo" o gorro de los quechuas y aimaras del altiplano peruano-boliviano, es copiado -en el argot del plagio se dice "estilizado"- por un modisto francés o una modista limeña y presentado como una "creación" en los desfiles de modas. Ese plagio parece una razón suficiente para decir que se trata de una "moda étnica", de un "mestizaje", o una "hibridación de culturas". Nada parece más "intercultural" que esa apropiación. Se acepta lo indígena sólo en pequeños fragmentos extraídos de sus contextos y reinstalados en paquetes llamados "modernos". Hay en los países andinos, sobre todo en Perú, una corriente de música llamada "chicha", "cumbia andina" o "tecno cumbia", que tiene de andino o de indígena sólo un pequeño fragmento de la melodía y nada más. Los versos en quechua, el diálogo de amor posible a través de metáforas con elementos de la naturaleza (ríos, árboles, cielos, aves) desaparecen. Lo nuevo es el machismo urbano, la pérdida de importancia de los versos, la ausencia de poesía, la coreografía con mujeres semidesnudas, las guitarras eléctricas, la percusión. A eso se llama "música andina moderna". Hay excepciones, sí, en algunas canciones que corresponderían a algo llamable nuevas crónicas urbanas (Montoya, 1996).

Desde el Banco Mundial y los Estados nación se toma la iniciativa para financiar miles de pequeños proyectos, con mucho dinero, cooptando a dirigentes indígenas contratados como consultores o técnicos con sueldos que no tendrían en cualquier otro trabajo. Esa es una estrategia para bloquear todo cuestionamiento del poder, para dividir a las organizaciones indígenas e impedir que éstas afirmen su autonomía y puedan ofrecer alternativas serias al orden establecido.

Lo último de esa estrategia es la propuesta de "inclusión". Así como toda política privada, pública y de ONGS debe tener un componente intercultural, ahora se propone la necesidad de un eje transversal de inclusión. Parece algo nuevo, pero si se observa atentamente la historia de los últimos setenta años -desde tiempos del indigenismo mexicano como producto de exportación a todo el continente, gracias a la mediación académica norteamericana de la llamada "antropología aplicada"- se encuentra la palabra integración, con el mismo propósito que se persigue ahora con la inclusión: que los indígenas dejen de ser lo que son y sean como los inventores de los proyectos de desarrollo capitalista quieren que sean. Una pregunta clave es quién quiere incluir a quién y para qué. 


\section{CATEGORIAS PARA NOMBRARNOS Y A QUÉ SE LLAMA PERÚ}

\subsection{Nosotros, los otros: categorías para nombrarnos e insultarnos.}

Cuando en 1492 Cristóbal Colón vio en el Caribe a los primeros hombres y mujeres de estas tierras, les llamó indios porque estaba convencido de que había llegado a la India por otra ruta. No preguntó cómo se llamaban y menos cómo les habría gustado que los llamasen. Ese cuidado en el trato de los otros sólo fue posible mucho tiempo después, en la segunda mitad del siglo XX, gracias a la emergencia indígena, étnica y política, y gracias -también- a una corriente dentro de la antropología.

La categoría "indio" fue sinónimo de habitante de América. Abya yala es, hoy, la palabra que usan las organizaciones indígenas de nuestro tiempo para designar el continente, en un legítimo esfuerzo para ofrecer una alternativa en la batalla contra el poder de las palabras. Entre 1492 y 1600, gruesamente la palabra indio designó a alguien habitante de este continente. Después de 1600, se convirtió en un objeto de propiedad por parte de los encomenderos y los futuros hacendados españoles: "Mis indios", "tus indios", en el sentido preciso de siervos o, prácticamente, esclavos. No se trataba sólo de la propiedad de la tierra, sino también de las personas, con el debido permiso de la Iglesia católica, por eso de la "esclavitud natural" tomada de los filósofos griegos y de la "servidumbre natural", reelaborada por los teólogos y muy astutamente usada por Juan Ginés de Sepúlveda en su Tratado sobre las justas causas para matar a los indios (1555).

Luego del encuentro de españoles e indígenas mujeres, forzado y/o consentido, el nacimiento de los hijos agregó en el lenguaje la palabra mestizo, derivada del latin "misticius" que quiere decir mixto o mezcla. Desde el primer momento los mestizos y mestizas, como descendientes de españoles e indígenas, fueron considerados, como inferiores o personas de menos valer, tanto desde la perspectiva española como desde el punto de vista indígena quechua, con la excepción de Garcilaso Inca de la Vega. Cito aquí, su célebre frase:

"A los hijos de español y de india nos llaman mestizos, por decir que somos mezclados de ambas naciones; fue impuesto en los primeros españoles que tuvieron hijos en indias, $y$ por ser nombre impuesto por nuestros padres y por su significación me lo llamo yo a boca llena y me honro con él aunque en Indias si a uno de ellos le dicen "sois un mestizo" o "es un mestizo" lo toman con menosprecio..." (Garcilaso, Los Comentarios reales, 1973, tomo III: 202).

Guamán Poma de Ayala que estaba convencido de que el mestizaje sería un factor decisivo para la desaparición de la sociedad inca. Para evitar la caída demográfica de su pueblo aconsejó al Rey de España que prohibiera el contacto entre “indias" y españoles y recomendó a sus hermanos preservar su unidad renunciando a todo vínculo con los europeos. 
"Dime autor, ¿cómo agora no multiplica los yndios y se hazen pobres? Diré a vuestra Magestad: lo primero que no multiplica porque lo mejor de las mugueres y donzellas lo toman los padres dotrinantes, comenderos, corregidores y españoles, mayordomos, tinientes, oficiales criados dellos y ancí hay tantos mesticillos y mesticillas en este rreyno... de todo lo dicho y daño de tanto agrauio se ahorcan ellos propios como los yndios changos de Andahuaylas. Está un cerrillo lleno de yndios, yndias. Quiere murir una uez no uerse en tanto daño" (Guamán Poma, 1980: 896-897).

"Y los yndios son propietarios naturales de este rreyno y los españoles de España. Acá en este rreyno son extrangueros, mitimays. Cada uno en su rreyno son propietarios lexítimos no por el rrey cino por Dios y la justicia de Dios. Hizo el mundo y la tierra y plantó en ellas cada cimiente, español en Castilla, el yndio en las yndias el negro en Guyneia... Porque es Inga y rrey y porque otro español ni padre tiene que entrar porque el Inga era propietario $y$ lexítimo rrey (Guamán Poma, 1980: 857-858).

"Digo a su Magestad que todos los españoles uiuan como cristianos, procuren casarse con su calidad ygual señora y dexen a las pobres yndias multiplicar... Luego que el que desuirgare a donzella yndia o que hiziere parir a la yndia casada o le fornicare forzalle, sean desterrados sey(s) años de galeras o a Chile y todos sus bienes sean penado para vuestra cámara y pague a la yndia y gastos de justicia" (Guamán Poma de Ayala, 1980: 902).

En el Vocabulario de la Lengua Aimara del padre Bertonio, cholo es sinónimo de perro: "chhulu, anocara, perro, mestizo de un mantinazo y perrillo". El Inca Garcilaso de la Vega escribe: "Al hijo de negro y de india o de indio y negra dicen mulato y mulata. A los hijos de estos llaman cholo; es vocablo de las Islas de Barlovento; quiere decir perro, no de los castizos sino de los muy bellacos y gozones; y los españoles usan del por infamia y vituperio" (1973, vol. III: 202).

Varallanos define al cholo como:

"Para nosotros el cholo peruano que ostenta, en cualquier dosis la sangre o la tradición de sus progenitores: europeos e indios. Hombre histórico que surgiera a raíz de la invasión del Imperio Inca por Pizarro y que fusiona a dos razas y a dos culturas; y encarna en sí la obra trascendente de la conquista española, particularmente en la media y alta geografía de los andes" (Varallanos, 1962: 32). El Diccionario de la real Academia define al cholo como "mestizo de sangre europea e indígena. Dice del indio que adopta los usos occidentales".

Nos choleamos, nos insultamos, y reproducimos el pasado al hablar de mis cholos o tus

2. "Las palabras perro, cholo y chulu eran pues, sinónimas; significaban o querían significar con ellas: infima condición social, baja ralea de un individuo" (Varallanos, 1962: 28). 
cholos como si fueran los indios siervos de la colonia. Cholo es también una palabra que identifica a los peruanos en el extranjero, equivalente de "gaucho" para los argentinos, "llanero" para los venezolanos y "huaso" para los chilenos. Cuando se usa el diminutivo -cholito, cholita- la palabra deja de ser discriminatoria, expresa afecto y, a veces, amor.

Al comienzo de la colonia, la palabra mestizo fue reservada para los hijos sólo de españoles y de indios y el vocablo casta fue usado para designar a los cruces entre españoles, indios y negros ${ }^{3}$. Luego de examinar los 20 cuadros que el Virrey Amat y Juniet encargó pintar sobre los diversos tipos de mestizos para obsequiarlos al rey Carlos III, el historiador Juan Carlos Estenssoro presenta cuatro bloques de mestizos a partir de los troncos español, negro e indio:

I. De Español y Negra redunda, 1, Mulato, 2, De mulato y Española Testerón o tercerón, 3, De Testerón y Española Cuarterón, 4, De Cuarterón y española Quinterón, 5, De Quinterón y Española Blanco o Español común. II, 6, De Negro y Mulato Sambo, 7, De Sambo y Mulata Sambohijo, 8, De Sambohijo y Mulata Tente en el Ayre, 9, De Tente en el Ayre y Mulata Salta atrás. III. De Español e India, 10, 'Mestizo Real', 11, De Mestizo e India Cholo, 12, De cholo e India Tente en el Ayre, 13, De Tente en el Ayre e India Salta atrás. IV. De indio y Negra, 14, Chino, 15, De Chino y Negra Rechino o Criollo, 16, De criolla y Negra Torna atrás" (Estenssoro, 1998: 81, la enumeración y el subrayado son de R.M.).

Si se recuerda que mulato deriva del animal mula, y se observa con atención el listado que acabo de citar, se impone una conclusión sencilla: las palabras para designar a los otros no son neutras, son esencialmente insultos. El poder separa, divide, inferioriza. Con esas palabras de menosprecio, desdén y odio, el racismo se instala en el inconsciente colectivo del Perú.

\section{De Indios a campesinos}

Karen Spalding en su excelente trabajo De indio a campesino (1974), mostró los primeros pasos de un largo proceso histórico en el que los quechuas y aimaras no fueran siervos de hacienda sino campesinos; es decir, parcelarios independientes articulándose lentamente al mercado colonial. Dice el Diccionario de la real Academia Española, que campesinos es una persona "Perteneciente o relativa al campo. Propia de él... que vive y trabaja de ordinario en el campo, silvestre, espontáneo, inculto...”. Esta definición reproduce el

3. "[el vocablo] castas, en plural, es empleado a menudo para designar, paradójicamente, no las tres naciones [españoles, indios y negros] sino sólo sus mezclas. Al estar la palabra mestizo reservada exclusivamente para el descendiente de españoles e indios, castas es empleada en el sentido que hoy día le damos (en castellano y en otras lenguas) al término mestizo" (Estenssoro, 1999: 76). 
prejuicio urbano contra los habitantes del campo.

Corresponde al gobierno del general Juan Velasco Alvarado (1969-1975) la decisión de renunciar oficialmente a las palabras "indio" e "indígena", y reemplazarlas por el vocablo campesino. Como la reforma agraria de 1969 acabó con los gamonales de horca y cuchillo y con los siervos de hacienda (hacienda runa, pongo, mitani-mujer sierva, colono, arrendire, sayaq runa-hombre quieto), no tenía sentido seguir llamando indios a quienes no querían ser llamados así. A nadie en el mundo le gusta ser tratado con desprecio. Se trató de un decreto-gesto de buena voluntad que excluyó los componentes básicos de lengua, cultura e identidad de las personas llamadas campesinas. Con ese gesto, Velasco y sus asesores civiles repitieron el viejo modelo europeo de la izquierda y su famosa alianza de la clase obrera y el campesinado, exportada al tercer mundo, y considerada como una de las claves de la llamada revolución democrático nacional. Directamente asociado a la condición campesina se halla el tema de la propiedad de la tierra y su injusta distribución entre un pequeño número de hacendados con grandes extensiones, una gran masa de campesinos con pequeñas tierras insuficientes para reproducir adecuadamente sus condiciones de existencia, y un importante número de campesinos sin tierra. En el caso peruano tuvimos casi un siglo de luchas por la tierra desde 1888 hasta 1980. El punto de partida fue el famoso discurso de Manuel González Prada en el teatro limeño Politeama en el que el célebre poeta, anarquista y terrateniente preguntó quiénes son los verdaderos peruanos y respondió rotunda y categóricamente "los indios", afirmó:

"No forman el verdadero Perú las agrupaciones de criollos y extranjeros que habitan la faja de tierra situada entre el Pacífico y los Andes; la nación está formada por las muchedumbres de indios, diseminadas en la banda oriental de la cordillera" (González Prada, 1960, t. 1: 67).

"Nuestra forma de gobierno se reduce a una gran mentira, porque no merece llamarse república democrática un estado en que dos o tres millones de individuos viven fuera de la ley” (González Prada, 1956: 58-59).

"Si del indio hicimos un siervo, qué patria defenderá, Como siervo de la Edad media, sólo combatirá por el señor feudal” (González Prada, 1960, t. 1: 65).

Fue también Manuel González Prada el primer en señalar que la solución para los problemas de los llamados indios de Perú, era fundamentalmente económica y social. Sobre esa huella tomó la posta José Carlos Mariátegui con una de sus tesis centrales: la solución de los problemas peruanos pasa por resolver el problema de la tierra y preparó las condiciones para que la Confederación Campesina del Perú, CCP, fundada en 1946, abriese el ciclo contemporáneo de luchas por la tierra. Hugo Blanco, como secretario de 
Reforma Agraria de la Federación Departamental de Campesinos del Cusco, fue clave para la primera reforma agraria en Perú, en 1962. Los movimientos guerrilleros, -Javier Heraud, 1963; Ejército de Liberación Nacional, en 1965 dirigido por Héctor Béjar, del Movimiento de Izquierda Revolucionara MIR (Luis De La Puente y Guillermo Lobatón; también en 1965)- inspirados por la revolución cubana, esperaban apoyar las tomas de tierras de Hugo Blanco, pero llegaron tarde, cuando ya la ola había pasado. Su derrota sirvió para que los militares extrajesen una conclusión política muy importante: sin una reforma agraria que resuelva los problemas del campo, volverán a aparecer otros líderes como Hugo Blanco y otros movimientos guerrilleros.

Inmediatamente después de las tomas de tierras, la Junta militar de 1962 y el primer gobierno de Belaúnde en 1964 intentaron reformas agrarias tímidas y parciales, hasta que la del general Velazco en 1969, la más importante y radical de todas, transfirió 10 millones de hectáreas y cambió el rostro agrario del país. La última, fue consecuencia de las acciones de Sendero Luminoso que obligaron a huir de los Andes a los últimos gamonales que escaparon de las reformas agrarias anteriores. En 1980, al inicio de su segundo gobierno, Fernando Belaúnde, decretó que la reforma agraria peruana había terminado.

En esos 90 años, la recuperación de la tierra, ocupó toda la atención de las organizaciones políticas de la izquierda peruana y opacó las reivindicaciones de lengua, cultura e identidad que se plantearon al mismo tiempo pero con una fuerza e intensidad muy pequeñas ${ }^{4}$. Luego de las tomas de tierras en Andahuaylas, en un artículo de la revista Marca, formulé la pregunta ¿Después de la tierra qué? Con esas tomas se cerraba el ciclo de luchas por la tierra. Paralelamente, desde la orilla ayacuchana del Río Pampas los senderistas anunciaban su tesis mayor: "Fuera del poder todo es ilusión" y se burlaban de quienes defendíamos las tomas de tierras en la orilla apurimeña de ese río, acusándonos de reformistas y simples "profundizadores" de la reforma agraria.

\section{De campesinos a indígenas}

Entre el 1 y 3 de julio de 1969, sólo una semana después de la promulgación de la ley de Reforma Agraria del general Juan Velazco Alvarado, tuvo lugar en Oxapampa la "Primera Conferencia de líderes Amuesha", que en mi opinión debe ser considerada como el punto de partida de las organizaciones indígenas amazónicas y del nuevo ciclo que podría llamar por la cultura y el poder en Perú, cuyo más reciente acontecimiento es la rebelión amazónica de Bagua en 2008 y 2009. En su "Memorial presentado al

4. En mi libro Lucha por la Tierra, Reformas Agrarias y Capitalismo en el Perú del Siglo XX (Montoya 1989: 27-32) he ofrecido una visión de conjunto de las luchas por la tierras y, particularmente en el capítulo I, se encuentra un largo cuadro con 83 reivindicaciones. Un último trabajo sobre la reforma agraria de 1969 es el de Enrique Mayer (2009), cuarenta años después. 
gobierno peruano por la Tribu Amuesha", acordaron, entre varios otros puntos: "2. Solicitar que se nos otorgue una mayor cantidad de terrenos, la extensión de los cuales debería guardar una justa proporción con el número de personas que vivirán en ello. $Y$ que al decidir el gobierno la cantidad de las tierras que nos va a adjudicar, considere los siguientes factores: la pobreza de los suelos, que exige que se otorgue una extensa cantidad de terrenos a fin que las futuras generaciones no se encuentren frente a tierras improductivas; b, la decisión de los pobladores de dedicarse a la ganadería, actividad que requiere una mayor área; c. a escasez monetaria de los Amuesha y la lejanía de sus reservas que demanda la garantía de zonas destinadas a la caza y a la pesca. 3. Hacer conocer que nuestro deseo es que se otorguen terrenos en forma de reservas comunales y no en parcelas individuales. Miraflores, Oxapampa, 3 de Julio de 1969". Firmaron los representantes de 20 comunidades. Francisco Conibo, de Maine, fue elegido Presidente del Comité que organizará, para el próximo año, la "Segunda Conferencia de Líderes Amuesha”. (KIARIO, 1: 13-14).

Este es el primer grito organizado de protesta indígena que abre el ciclo contemporáneo de movimientos políticos indígenas. La palabra territorio aún no aparecía, pero el reclamo del bosque como extensa propiedad colectiva ya estaba presente y abrió el camino.

En el último tercio del siglo XX, surgieron en América Latina los movimientos indígenas étnicos y políticos como un nuevo actor y sujeto político. El levantamiento indígena en Ecuador (1990), La marcha por la Dignidad y el territorio en Bolivia, (1990) y la aparición del Ejército Zapatista de Liberación Nacional en México (1994) fueron los acontecimientos más importantes. Pero la historia de esa emergencia indígena se remonta a los años 60 y 70 del siglo XX. Para sorpresa de las clases políticas de los Estados naciones, aparecieron -como dicen los Zapatistas- nuevas voces de la tierra, los invisibles reclamando ser oídos y tomados en cuenta, trayendo nuevas propuestas y otras maneras de hacer política. Un listado de nuevas reivindicaciones nunca antes defendidas por los partidos tradicionales de izquierdas o derechas fue forjándose paso a paso. En primer lugar, el territorio, como la tierra extensa identificada con el bosque donde son posibles la vida y la cultura de los pueblos indígenas. Luego, la cultura, la lengua, la identidad, el derecho a la autodeterminación, a un gobierno propio, sin que eso quiera decir que pretenden separarse de los Estados naciones a los que pertenecen sino, esencialmente, disfrutar de autonomías dentro de las estructuras del poder. Siguen después la defensa de la naturaleza, entendida como la Mama Pacha, los saberes andinos y amazónicos, una espiritualidad fundada en la gratitud, respeto y amor con la tierra, los ríos y el mar, que ofrecen los alimento no sólo a los pueblos indígenas sino a toda la especie humana. Ya está en proceso de elaboración una propuesta del Allin kawsay o buen vivir como alternativa para un desarrollo alternativo al llamado desarrollo que no es otra cosa que el desarrollo capitalista del que son excluidos todos los pueblos indígenas 
y las capas populares.

El terreno parece propicio para que la política tome en cuenta a la cultura como uno de sus componentes, en la medida en que esta es sinónimo de pueblos indígenas que viven, sufren, luchan, reclaman y quieren un mundo mejor y no es sólo un listado de bellas costumbres, leyendas o canciones. Por eso, la relación de la cultura con el poder es un problema central. No tiene sentido defender sólo el carácter multicultural y plurilingüe de nuestras sociedades mientras el poder sigue en manos de quienes oprimen a los pueblos indígenas. Como lo señalé en parte I, al Banco mundial, al BID, a los gobiernos, a las clases políticas, y aún a una buena parte de los sectores progresistas, sólo les interesa que las tradiciones sean mantenidas, que la metáfora “Todas las sangres” sea tomada sólo como un listado de diferencias, como una tarjeta postal que invita al turismo y que sólo debemos apreciar y aplaudir siempre que el poder no sea cuestionado, que las reglas del capitalismo sean respetuosamente seguidas y que los indígenas no tengan poder alguno para tomar sus propias decisiones y definir su propia suerte.

Parece ya clara la convicción de la necesidad que los pueblos indígenas tienen de organizarse políticamente, tener sus propios partidos y movimientos para no ser manipulados y engañados por los caciques y caudillos de la política tradicional. Uno de los mensajes más ricos y fecundos de los zapatistas de México es su convicción de construir otras relaciones sociales horizontales como alternativa a la generalizada lucha por el poder como si el poder fuese una casa que se conquista, se alquila u ocupa. Construir otro poder significa inventarlo horizontalmente renunciando a la metáfora De arriba y abajo. Hemos sido prisioneros de la idea de que el poder viene siempre de arriba y están siempre arriba los que mandan y abajo los que obedecen. No se trata de invertir la torta y proponer la dictadura de los de abajo sobre los de arriba porque cambiando de dictador y de víctimas, la dictadura continúa y las víctimas no desaparecen. Resulta evidentemente inútil la metáfora de la sociedad como un edificio de dos pisos, arriba y abajo. Con los movimientos indígenas étnicos y políticos aparecen los colores de la tierra; es decir, nuevos rostros, nuevos apellidos y nuevas prácticas suficientemente visibles como para romper con la monotonía de las clases políticas coloniales. Los indígenas ecuatorianos han construido un movimiento político desde abajo, paso a paso, en abierto contraste con los movimientos de caudillos, desde arriba.

Lo nuevo aparece en el horizonte siempre enredado con lo viejo; nada es puro y transparente ni todo es color de rosa. La inexperiencia política de los hermanos indígenas ecuatorianos, particularmente en su alianza con un caudillo militar, el coronel Lucio Gutiérrez, es una durísima lección de la realidad, en pleno procese de asimilación. En política son indispensables las alianzas y aún queda un largo trecho para replantearlas y no volver a cometer los errores del pasado; más aún si es necesario admitir que los pueblos indígenas no pueden resolver solos sus problemas. No son fáciles de eludir 
las tentaciones del poder, sobre todo cuando en el pasado sólo se conoció la pobreza y la invisibilidad. Tampoco la unidad entre indígenas es fácil porque el componente de división es una herencia histórica, debidamente alimentadas desde el poder colonial. Por otro lado, las distancias entre intelectuales indígenas de las direcciones étnicas y políticas y las comunidades de base siguen siendo importantes.

Es adverso el contexto en el que se produce la emergencia de este nuevo actor y sujeto político. Por el colonial e histórico desprecio por lo indio, debido al extraordinario racismo existente en los Estados naciones en general y andinos en particular, los movimientos indígenas deben contar con sus propias fuerzas, salvo el caso de Bolivia. Poco a poco, comienza a aparecer una solidaridad y simpatía, como la que se produjo en Bagua en agosto de 2008 y en junio de 2009. "Todos somos indígenas" es una frase cargada de futuro. No puede ser mayor la oposición de las clases políticas a estos Movimientos indígenas, particularmente la de Alan García, su partido, y sus aliados en la derecha, el fujimorismo y los social cristianos. También cuentan en contra el narcotráfico y los restos del senderismo.

Entre la población andina quechua y aimara y la masa de migrantes en Lima y las principales ciudades en el país, el tema en discusión es si son indígenas o no; sí deben ser indígenas o no. La simpatía con Alberto Pizango y los pueblos amazónicos por su coraje y firmeza, los lleva a replantear su condición de campesinos que fue una especie de refugio para no sentirse lo último en la sociedad. Ser indígena hoy, en Perú, en los países andinos, en América Latina y en el mundo significa, defender una cultura, una lengua, una identidad, una esperanza política muy diferente a las del pasado. Ya no se trata de un insulto como antes. Indígena y originario del suelo americano, de Abya yala son sinónimos. Aparece en el horizonte la rebelión amazónica de Bagua como un ejemplo a seguir. Sin embargo, es fuerte aún el peso de la vergüenza de ser lo que se es y valerse de máscaras para parecerse a quienes se imponen como el modelo a seguir. Del modo cómo se resuelva el conflicto entre la adhesión a las máscaras y la aceptación de sí mismos dependerá la suerte de los movimientos indígenas aimaras y quechuas en Perú.

\subsection{Una mirada histórica: ¿Qué fue y qué es el Perú?}

Me parece pertinente introducir aquí la manera cómo fue visto el Perú cuando los españoles oyeron en Tumbes, antes de subir a Cajamarca, que nuestra tierra-río se llamaba Pilú-Pelú-Perú. Desde 1532 hasta 1781, la palabra Perú identificó al "país de los incas" y fue sinónimo de un reino sin hambre, de una vasta región de abundancia, de oro y grandes fortunas. Hasta fines del siglo XIX, en Europa "Vale un Perú", quería decir, es oro, vale mucho, muchísimo, y el "País de Jauja" quería decir, tierra de comida abundante, porque el recuerdo del placer de los españoles que en su viaje hacia Cusco al engordar y descansar en Hatun Xauxa, habría sido extraordinario e imborrable. 
Después de la derrota de Túpac Amaru. En 1781, la Corona española ordenó que se borre la memoria de los incas. En su condición de Inca y Rey, Túpac Amaru condujo la revolución nacional indígena más importante de América, atacando las bases mismas del imperio colonial español: muerte a los corregidores, destrucción de los obrajes, inmediata eliminación de la mita y los repartimentos. Si hubiera triunfado, seguramente Cusco habría recuperado su condición de capital del reino. Hasta 1780 la propia corona reconoció incas coloniales como parte de su estrategia política al usar a los curacas indios como visagras del sistema de poder. País de los incas quería decir también país de la Monarquía española, dueña y señora del reino.

Si el Perú dejó de ser el "país de los incas", entre 1781 y 1821, la pregunta inevitable habría sido y ahora país de qué. Era imposible que los chapetones pretendieran cambiar de nombre y llamarle al Perú algo así como "país de españoles". Ya los vientos de independencia aparecían y crecían en la periferia, principalmente en Caracas y Buenos Aires. Ese fue el momento en el que los criollos pensaron y llegaron a la conclusión de que el Perú era de ellos. En 1821 nació la República criolla, para los criollos, "sin y en contra de los indios", según la certera frase del amauta José Carlos Mariátegui.

El nuevo Estado Nación surgió como un Estado unicultural: un estado, una nación, una cultura, una religión, una lengua, un Dios verdadero, en un territorio en el que tres cuartas partes de la población vivían en una diversidad extraordinaria de pueblos, lenguas, culturas y creencias religiosas.

Desde la segunda mitad del siglo XX, la condición pluri y multi cultural y linguística ha derrotado ya al Estado nación unicultural y las bases de la vieja república criolla ya no tienen la fuerza de 1821. Está en marcha un proceso de cambio político muy importante. Lo mismo ocurre en todos los países de fuerte composición indígena de América Latina, con diferencias de ritmos y de fuerzas. De acuerdo a la nueva constitución, democráticamente aprobada por amplia mayoría de bolivianos, el país cambió de nombre y se llama ahora "Estado Plurinacional de Bolivia". Ese parece ser un enorme desafío en el horizonte.

\section{3. ¿Cuál es el porvenir de la cultura quechua?}

Para terminar, creo útil una reflexión más sobre la cultura y la política en Perú a partir de la pregunta ¿Cuál es el porvenir de la cultura quechua? La cultura se vuelve política en el preciso período en el que su desaparición aparece también en el horizonte. He consagrado a este tema un largo trabajo de campo en Villa el Salvador y Lima y mi libro Porvenir de la cultura quechua en Perú que aparecerá en abril de 2010 ofrece elementos de respuesta (Montoya, 2010, en prensa). Si cada semana se pierde una lengua indígena en el mundo, la tendencia dominante es también la desaparición de las culturas, con una frecuencia sin duda menor. Dos son las respuestas a la pregunta. Una: si la política oficial 
de la república criolla se mantiene, desaparecerá. Dos: se mantendrá y se desarrollará si todos los quechuas asumimos políticamente su defensa, a partir de las comunidades, los migrantes en Lima y las ciudades en la Costa, Sierra y aún en la Amazonía y el conjunto de profesores de educación bilingüe e intercultural. Una alianza con todos los pueblos indígenas del país y con las capas populares y parte de las capas medias sería el refuerzo indispensable. El reto es salir de la vergüenza para asumir lo que somos y dejar atrás las máscaras para aparentar lo que no somos. 


\section{REFERENCIAS BIBLIOGRÁFICAS}

ARGUEDAS, José María (1964) Todas las sangres. Buenos Aires: Novela, Editorial Losada.

CONTRERAS BASPINEIRO, Alex (2008) Bolivia: Fascismo racista en Sucre. En ALAI AMLATINA http://www.ecaminos.org/leer.php/5099

DE LA VEGA, Garcilaso (1973) [1609] Los Comentarios reales de los incas. Lima: PEISA. Biblioteca Peruana.

ESTENSSORO FUCHS, Juan Carlos (1998) "Los colores de la plebe: razón y mestizaje en el Perú colonial". En Museo de Arte de Lima, Los cuadros del mestizaje del Virrey Amat: La representación etnográfica en el Perú colonial. Lima, pp. 67-107.

GONZÁLEZ PRADA, Manuel (1956) [1888] Ensayos escogidos. Selección y prólogo de Augusto Salazar Bondy, Patronato del Libro Peruano, primer festival. Lima.

GONZÁLEZ PRADA, Manuel (1956) [1904] "Nuestros indios”. En Ensayos escogidos. Selección y prólogo de Augusto Salazar Bondy, Patronato del Libro Peruano, primer festival. Lima.

GONZÁLEZ PRADA, Manuel, (1960) Páginas libres. Ediciones populibros. Lima.

GUAMÁN POMA DE AYALA, Felipe (1980) El Primer nueva corónica y buen gobierno. Edición crítica de John Murra y Rolena Adorno, Traducción y análisis textual del quechua por Jorge Urioste. México: Siglo XXI. Nuestra América, 3 vols.

HUNTINGTON, Samuel P. (1997) El Choque de civilizaciones y la reconfiguración del orden mundial. Buenos Aires: Paidós.

KIARIO, Boletín del Centro de Investigaciones de Selva (1969), 1. Universidad Nacional Mayor de San Marcos, Instituto Raúl Porras Barrenechea. Lima.

MAYER, Enrique (2009) Cuentos feos de la reforma agraria peruana. Lima: Instituto de Estudios Peruanos.

MATTO DE TURNER, Clorinda (2004) [1889] Aves sin nido. Buenos Aires: Stock Cero. MONTOYA ROJAS, Rodrigo (1989) Lucha por la Tierra, Reformas Agrarias y Capitalismo en el Perú del Siglo XX. Lima: Mosca Azul Editores.

MONTOYA ROJAS, Rodrigo (1996) "Música chicha: cambios de la canción andina quechua en Perú". En Max Peter Bauman, (Ed) Cosmología y música en los Andes. Madrid: Biblioteca Ibero Americana.

MONTOYA ROJAS, Rodrigo (2009) Con los rostros pintados: tercera rebelión amazónica en Perú, agosto 2008- junio2009 www.servindi.org.pe, www.democracia global.org Universidad Nacional Mayor de San Marcos. 
SPALDING, Karen (1974) De indio a campesino. Lima: Instituto de Estudios Peruanos. VARALLANOS, José (1962) El cholo y el Perú, introducción al estudio sociológico de un hombre y un pueblo mestizos y su destino cultural. Buenos Aires: Imprenta López. 